\title{
Real Time Hotspot Detection System Using Scan-Method for PV Generation System
}

\author{
Kazutaka Itako, Bakhsh Hossam, Tsugutomo Kudoh and Qixin Huang \\ Electrical and Electronics Engineering Department, Kanagawa Institute of Technology, Atsugi 243-0292, Kanagawa, Japan
}

Received: April 28, 2016 / Accepted: May 9, 2016 / Published: June 30, 2016.

\begin{abstract}
This paper presents a real time hotspot detection system using scan-method about PV (photo voltaic) solar panel $I-V$ characteristic based on the periodic inspection of the $I-V$ curve of the PV panel in real time. The $I-V$ tracking is performed by the means of periodic current sweeps during the normal operation of the panel. The current variation in a specific voltage range allows to distinguish hotspot cells from normal cells. In case if partial shadowing occurs to the PV panel, the PCS (power conditioning system) gives an immediate judgment whether hot-spot arises from one of the cells or not by applying the scan-method. The PCS is programed to calculate the current rate depending on the difference in the current divided by the short circuit current. From the experimental results, it is clarified that the hot-spot cells can be determined regardless of the solar intensity radiation.
\end{abstract}

Key words: Hot-spot, detection system, real-time, PCS, PV solar panel, DC-DC converter.

\section{Introduction}

\subsection{General}

Currently, a feed-in tariff system requiring utility providers in Japan to purchase the maximum amount of electricity generated by non-residential PV power systems is being implemented, and the production of PV modules and the number of installations has been increased rapidly. Accordingly, the number of failures has also increased. From reports on the causes of the failures, it is understood that many faults are a result of the hot-spot phenomenon. This is a phenomenon in which the entire or part of the cell becomes hot when partial shadowing occurs. If the partial shadowing continues for a long period of time, the temperature of the cell rises and causes deformation in the surface resin with the risk that the cell will break and burn in some cases. While there are methods for measuring temperature, such as using an infrared camera, for the purpose of checking for hot-spots, the measurement

Corresponding author: Kazutaka Itako, Ph.D., professor, research field: power electronics. instruments are expensive, and a lot of time and effort is required. Therefore, the authors previously investigated the hot-spot phenomenon based on crystal defects and the simple hot-spot detection method [1, 2]. In the present studies, based on these findings, we present a PCS (power conditioning system) to detect the hot-spot phenomenon in real-time based on the new MPPT (maximum power point tracking) algorithm "scan-method" and analyzing the effect of partial shadow on the PV panel $I-V$ curve [3].

\subsection{Hot-Spot Phenomenon}

A hot-spot situation is existent when a solar cell within a panel generates less current than the string current of the panel. This occurs when the cell is totally or partially shaded, cracked, or electrically mismatched. In such case, the defective cell becomes reverse biased and dissipates power in form of heat, leading to excessive efficiency degradation of the related PV panel [4-7]. Particularly, the severeness of degradation directly correlates with the heat dissipation under reverse bias. The presented approach suggests that the use of developed power conditioner 


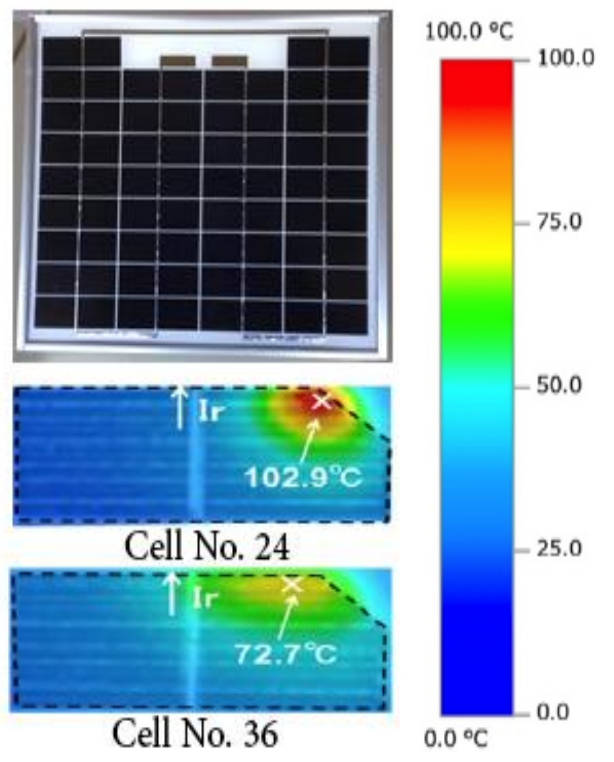

Fig. 1 Example of hot-spot cells by infrared camera.

as a system for detecting possible malfunctions, e.g. hot-spots in Fig. 1, loss of adhesion, etc.

Hot-spot arise can cause major defection in the module and affect the whole system. Moreover, about $15 \%$ of reported failure cases of PV solar cell system in Japan were due to panels' malfunction [8].

\section{Detection Method Theory}

Shadowing a cell or a part of it has a direct impact on the current path inside the module. Fig. 2a shows the current path in no shadowing condition. The current flows normally through the two clusters while the bypass diodes are in OFF state. Therefore, shadowing a normal cell, which reverse leakage current is low, leads the whole current to skip the string of series connected cells in the cluster of the shaded cell to flow through the bypass diode as illustrated in Fig. $2 b$.

On the other hand, the hot-spot cell, which reverse leakage current is high, operates as a resistance under the shadowing condition and the whole current is leaked through the shaded cell while the bypass diode is in OFF state as illustrated in Fig. 2c. The lost power is dissipated to heat and formed the hot-spot phenomenon. Fig. 3 shows the difference in the reverse leakage current between the normal cell and the hot-spot cell.

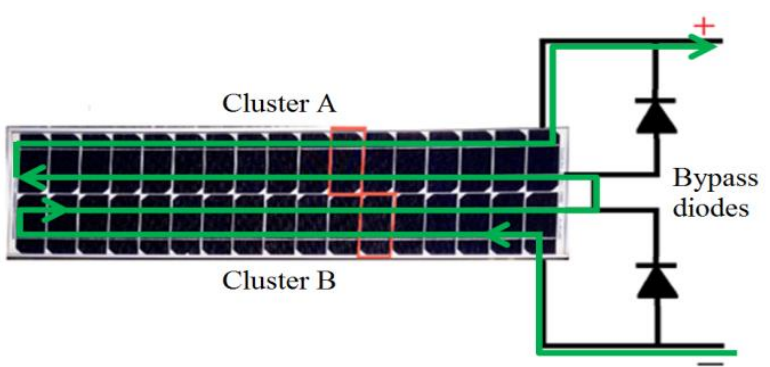

(a) No shadowing condition

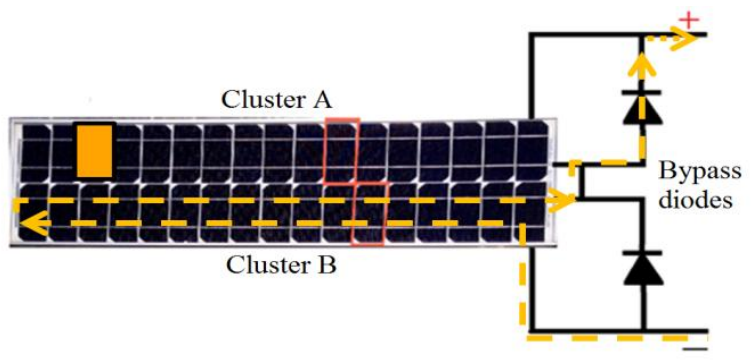

(b) Normal cell is shaded

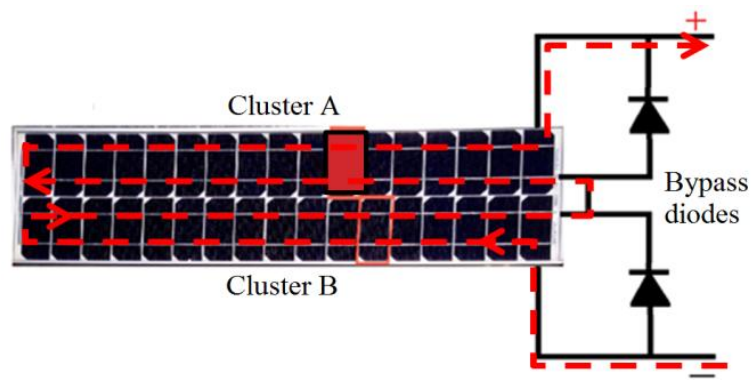

(c) Hot-spot cell is shaded

Fig. 2 Current path of the PV solar panel.

\section{Hot-Spot Detection Method}

Table 1 shows the specification of PV solar panel model number GT133 at $25^{\circ} \mathrm{C}, 1,000 \mathrm{~W} / \mathrm{m}^{2}$.

As a preparation step, hot-spot cells of the used panel were determined by shadowing each cell of the panel individually and observing the changes in the output current. Based on the current path theory two cells were determined to be hot-spot cells and they are pointed in red in Fig 3 .

Table 1 PV solar panel specifications.

\begin{tabular}{ll}
\hline PV solar panel Mmodel number: GT133 \\
\hline Maximum power & $50 \mathrm{~W}$ \\
Maximum voltage & $20.5 \mathrm{~V}$ \\
Maximum current & $3.35 \mathrm{~A}$ \\
Operation voltage & $16.4 \mathrm{~V}$ \\
Operation current & $3.05 \mathrm{~A}$ \\
\hline
\end{tabular}




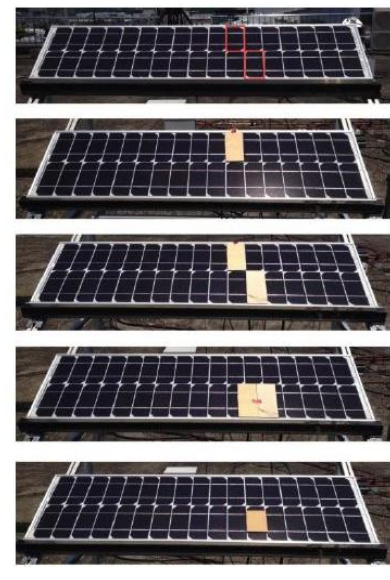

Unshaded

One cell shaded

Two cells shaded

Big shadow

Small shadow

Fig. 3 Patterns of partial shading.

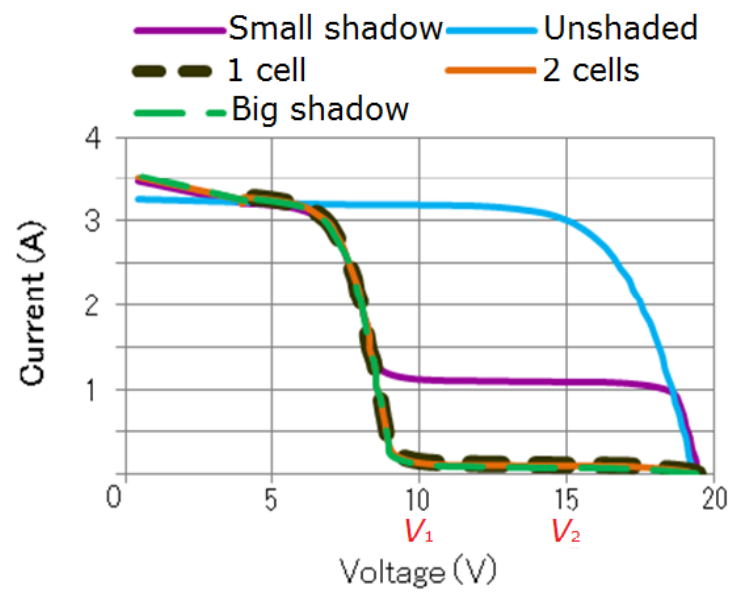

Fig. $4 I-V$ characteristics of normal cell.

Fig. 3 shows different shadows applied to the hot-spot cells of the panel. The same cases of shadowing were applied to normal cells also to observe the difference between all the cases and collect many results for comparison.

Depending on the results of the experiments and the readings obtained, when normal cells are shaded there is a sudden drop in the current as in Fig. 4 because the current skips the whole string of cells to flow toward the bypass diode. In case of shadowing hot-spot cells the current decreases linearly as shown in Fig. 5 and this inclination seems more evident between point $10\left(V_{1}\right)$ and point $15\left(V_{2}\right)$ volts. The linear decrease under big shadow condition due to the panel's operating current exceeds the short circuit current of a low-current-producing cell. In 1 cell shading and small shadow conditions, the inclination is similar but

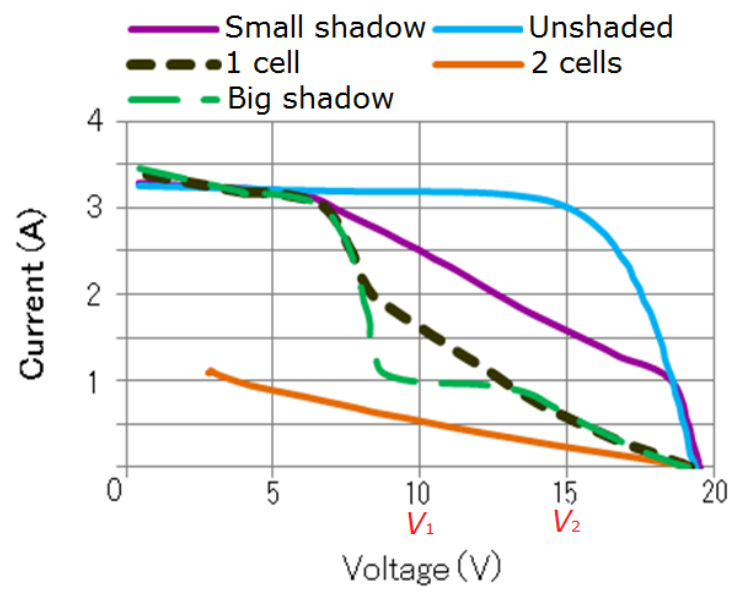

Fig. 5 I-V characteristics of hot-spot cell.

the amount of flowing current is different. The reason is considered that the resistance value is approximately equal but the size of the coverage area determines the amount of flowing current. For 2 cells shading condition, the resistance value becomes larger and accordingly the flowing current decreases. We relied upon the current inclination of all conditions to differentiate between normal cells and hot-spot cells.

\section{Investigation of Detection Criterion}

This system is based on calculating the current difference between the two points $10\left(V_{1}\right)$ and $15\left(V_{2}\right)$ volts divided by the short circuit current $\left(I_{0}\right)$ to regard the changes in the solar radiation intinsity.

Current change rate $=$

$$
\left(I_{V 1}-I_{V 2}\right) / \text { short circuit current } I_{0}
$$

where, $I_{0}$ is the short circuit current when there is no shadow applied to the panel.

Tables 2 and 3 summarize the result of the current change rate for the $I-V$ characteristics of normal cells and hot-spot cells when partial shadowing is applied.

According to the results of current change rate illustrated in Tables 2 and 3, if the current change rate value becomes 0.1 and over it that means there is a hot-spot cell in the PV solar panel. On the contrary, if the result does not exceed 0.1, it means the PV solar panel is function properly. This result is the basis to express the proposed real time hot-spot detection system. 
Table 2 Normal cells.

\begin{tabular}{llllll}
\hline State of shadow & Unshaded & Small shadow & 1 cell shaded & 2 cells shaded & Big shadow \\
\hline Current change rate & 0.06 & 0.03 & 0.01 & 0.02 & 0.02 \\
\hline
\end{tabular}

Table 3 Hotsopt cells.

\begin{tabular}{llllll}
\hline State of shadow & Unshaded & Small shadow & 1 cell shaded & 2 cells shaded & Big shadow \\
\hline Current change rate & 0.06 & 0.30 & 0.31 & 0.25 & 0.13 \\
\hline
\end{tabular}

\section{Proposed Real Time Hotspot Detection System}

As shown in Fig. 6 the solar cell is connected in series to the required power level. The power from the solar cell, whose voltage is boosted by a step-up DC-DC converter, is then applied to the electronic load. The control system detects the solar cell voltage $V$ and the solar cell current $I$ in real-time. And these values undergo in an A/D conversion to the DSP (digital signal processor).

The nominal optimum operating voltage and current for the solar cell panel are $16.4 \mathrm{~V}$ and $3.05 \mathrm{~A}(50 \mathrm{~W})$, respectively. The panel is connected to the DC-DC converter with constants of $L=800 \mu \mathrm{H}$ and $C=1,000$ $\mu \mathrm{F}$. As a load, electronic load (20 V: constant voltage mode) was used. The switching frequency $f_{C}$ was set to $20 \mathrm{kHz}$ and the detection cycle $T$ was set to $10 \mathrm{~s}$. A DSP was used to control the computational processing. The vertical axis resolution for the A/D converter was 12 bits with a sampling frequency of $100 \mathrm{kHz}$.

This system is based on the new $I-V$ characteristics scan-type MPPT control method for PV generation system [9] which is developed in our lab. As an addition to maintain the low value of $L$ and outstanding effectiveness in partially shaded environments, the system is developed to detect hotspot phenomena in real time.

The following describes the procedure of the scan-method. With the scan-method, to operate the solar cells at the optimum operating voltage $V_{O P}$ during maximum power $P_{\max }$ and to detect the hot-spot phenomenon, the $I-V$ characteristics of the solar cells are scanned instantaneously and the PWM (pulse width modulation) control is used to perform tracking control.

Fig. 7 displays a conceptual diagram that depicts the operational waveforms for the scan-method [10]. The carrier wave (serrated wave) is compared to the reference signal wave using a comparator, which yields the PWM control signal. For the scanning process, the solar cell voltage $V_{P V}$ is assumed to be zero to make the solar cell current $I_{P V}$ equal to the short circuit current ISC. In $P_{\max }$ detection state, the $I_{P V}$ is controlled to the following reference current Iref from ISC to zero by the PWM control.

$$
I_{r e f}=-\left(I_{S C} / T_{\text {Dref }}\right) t+I_{S C}
$$

$I_{S C}$ is a short circuit current (A) and $T_{D r e f}$ is the $I-V$ characteristics scanning interval (s). In this period, the solar cell current $I_{P V}$ is multiplied by the measured solar cell voltage $V_{P V}$ to determine the maximum power point, and the values of the solar cell current $I_{V I}$ and $I_{V 2}$ are detected when the solar cell voltage reaches the points $V_{1}$ and $V_{2}$ to determine the presence of the hot-spot. Hereafter, the solar cell voltage $V_{P V}$ is controlled to trail the resulting optimal operating voltage $V_{O P}$. As the final step, the tracking operation interval is switched to a high frequency $f=1 / T$ in the

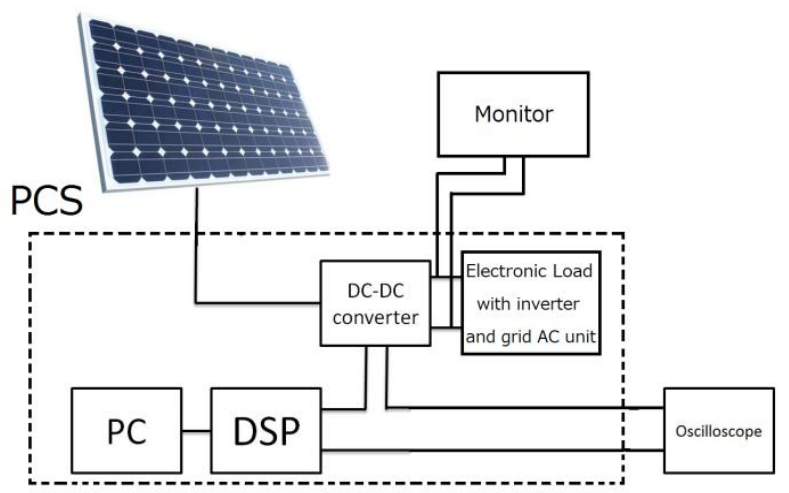

Fig. 6 Real-time hot-spot detection system connection. 


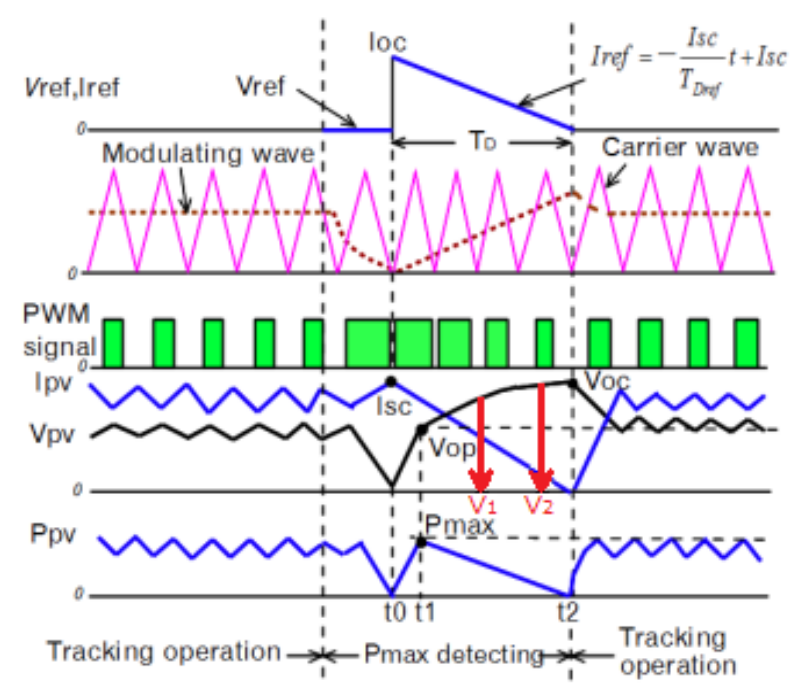

Fig. 7 Scan-method principle diagram.

range of tens of $\mathrm{kHz}$ to regulate the output voltage of the DC-DC converter. The output voltage is controlled so that the solar cell voltage $V_{P V}$ is equal to the optimal operating voltage $V_{O P}$.

Fig. 8 provides the operational waveforms of the system. The DC-DC converter scans the incoming current and voltage of the panel every 10 seconds to detect the maximum operational power point and to give a judgment whether hot-spot cell is existed or not in real-time and while the system is operating.

Fig. 8a is a case of shadowing a normal cell. The output power is greatly decreased as a result of the shadowing but in 10 seconds point the scanning operation is performed and the output power is ensured to a certain level while the hot-spot flag remains zero. In 22 seconds, the shadow is removed and the output power is somewhat increased. Therefore in 30 seconds the scanning operation is performed, the output power is fully recovered and the hot-spot flag also remains zero.

Fig. $8 \mathrm{~b}$ shows the operational waveform when hot-spot cell is shaded. The output power is greatly decreased as a result of the shadowing. In 10 seconds point, the scanning operation is performed, the output power is ensured to a certain level and the hotspot flag becomes $5 \mathrm{~V}(\mathrm{ON})$ so we can consider that the hot-spot is detected. In 23 seconds, the shadow is

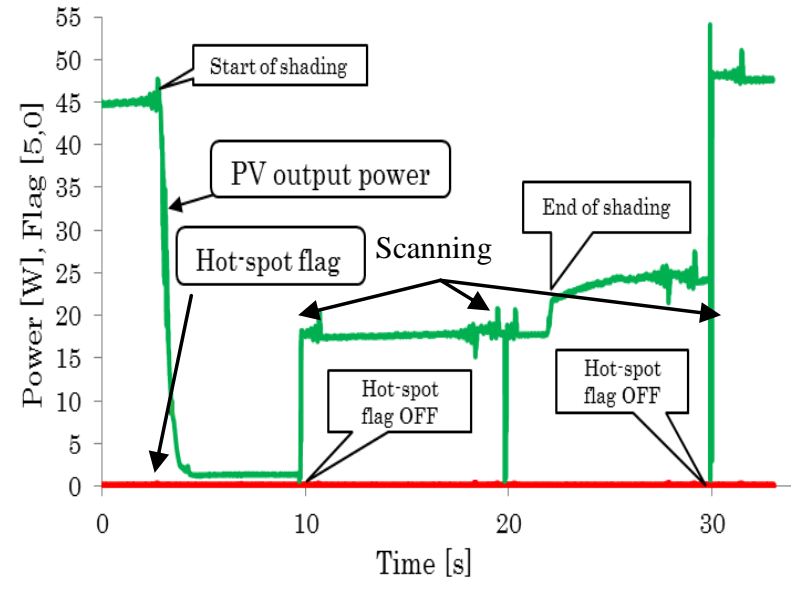

(a) No hot-spot case

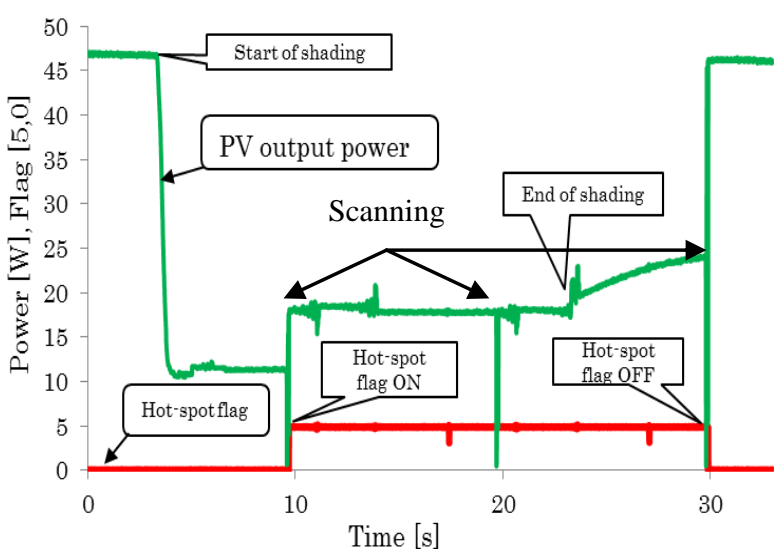

(b) Hot-spot existed case

Fig. 8 Operational waveforms of hot-spot detection.

removed and the output power is somewhat increased. In 30 seconds the scanning operation is performed, then the output power is fully recovered and the hot-spot flag becomes zero.

\section{Conclusions}

The aim of this research is to find an easy and sophisticated way to detect the hot-spot phenomenon instead of the traditional methods currently used by the infrared camera or measuring the change in the current by covering each cell individually. The proposed system will greatly help in reducing the risk of hot-spot phenomenon, and increase the performance of the solar cell system and help in the maintenance of the solar system. 
To build an integrated system that can determine the presence of the hot-spot phenomenon in one cell of the panel in real-time, in the preparation experiment, the hot-spot cells were determined by shadowing each cell individually and calculating the current ratio depending on change of the short-circuit current.

The first part of this research investigates about the PV solar panel $I-V$ characteristic to find a way to distinguish between normal cells and hot-spot cells depending on the changes of the panel output current which helps to design the real-time hot-spot detection system. From the experimental results, it is clarified that the hot-spot cells can be determined by the current change rate equation.

Depending on the results of the first experiment and using the new MPPT algorithm "scan-method", we were able to program the PSC to track the current and voltage of the panel in real time to give an immediate judgment whether hot-spot arises from one of the cells or not. Over testing the program by the DSP in different times and solar radiation intensity, the effectiveness of the result of this experiment is verified and proved that hot-spot phenomenon can be detected by the current change rate in case of partial shadowing.

\section{References}

[1] Watanabe, S., Iijima, T., Ohya, H., Kudoh, T., and Itako, K. 2013. "Study on Temperature and Fundamental
Characteristics of Hot-Sot of Single-Crystal Photovoltaic Cell by the Amount of Solar Radiation." In Proceedings of the JSES/JWEA Joint Conference.

[2] Kudou, H., Sugiyama, T., Kudoh, T., and Itako, K. 2013. "Prototype of the Hot-Spot Rough-Diagnosis Equipment Using Projector for PV Module." In Proceedings of the JSES/JWEA Joint Conference.

[3] Bakhsh, H., Alsharedah, A., and Itako, K. 2014. "Real-time Hot-spot Detection System." In Proceedings of the 26th Society of Advanced Science Intelligent Symposium.

[4] Hoyer, U., Burkert, A., Auer, R., and Buerhop-Lutz, C. 2009. "Analysis of PV Modules by Electroluminescence and IR Thermography." In Proceedings of the 24th European Photovoltaic Solar Energy Conference, 3262-6.

[5] Luque, A., and Hegedus, S. 2003. Handbook of Photovoltaic Science and Engineering. Chichester: Wiley-Interscience.

[6] Simon, M., and Meyer, E. L. 2010. "Detection and Analysis of Hot-Spot Formation in Solar Cells." Solar Energy Materials and Solar Cells 94 (2): 106-13.

[7] Wohlgemuth, J., and Herrmann, W. 2005. "Hot Spot Tests for Crystalline Silicon Modules." In Proceedings of the 31st IEEE Photovoltaic Specialists Conference, 1062-3.

[8] Katoh, K. "Failure Case File of Solar Power Generation System." Nikkan Kogyo Shimbun.

[9] Itako, K. 2012. "New I-V Characteristics Scan-Type MPPT Control Method for PV Generation System." Journal of Technology Innovations in Renewable Energy $1(2): 87$.

[10] Itako, K. 2014. "High Efficiency PCS with Scan-Type MPPT Control for a Grid-Connected PV Power Generation System." Journal of Energy and Power Engineering 8 (1): 137-43. 